\title{
Impact of climate change and human-mediated introgression on southern European Atlantic salmon populations
}

\author{
J. L. HORREO*, G. MACHADO-SCHIAFFINO*, F. AYLLON†,A. M. GRIFFITHS \\ D. BRIGHT§, J. R. STEVENS $\uparrow$ and E. GARCIA-VAZQUEZ* \\ *Department of Functional Biology, University of Oviedo, C/Julian Clavería s/n, 33006 Oviedo, Spain, †Departament Genetica $i$ \\ Microbiologia, Universitat Autonoma de Barcelona, Barcelona, Spain, †Marine Biological Association of the UK, The Laboratory, \\ Citadel Hill, Plymouth PL1 2PB, UK, §Westcountry Rivers Trust, Rain-Charm House, Kyl Cober Parc, Stoke Climsland, Callington, \\ Cornwall PL17 8PH, UK, -School of Biosciences, University of Exeter, Exeter EX4 4PS, UK
}

\begin{abstract}
This study focuses on temporal changes in Atlantic salmon (Salmo salar) populations from the vulnerable periphery of the species range (northern Spain). Using microsatellite markers to assess population structuring and introgression of exogenous genes in four different temporal samples collected across 20 years, we have determined the relative weights of climate and stocking practices in shaping contemporary regional population genetic patterns. Climate, represented by the North Atlantic Oscillation Index, was identified as the main factor for determining the level of population genetic differentiation. Populations within the region have become homogenized through gene flow enhanced by straying of adult salmon from natal rivers and subsequent interchange of genes among rivers due to warmer temperatures. At the same time, and in line with documented changes in stock transfer strategies, evidence of genetic introgression from past stock transfers has decreased throughout the study period, becoming a secondary factor in erasing population structuring. The ability to disentangle the effects of climatic changes and anthropogenic factors (fisheries management practices) is essential for effective long-term conservation of this iconic species. We emphasize the importance of evaluating all factors which may be linked to stocking practices in vulnerable species, particularly those sensitive to climate change.
\end{abstract}

Keywords: anthropogenic-mediated migration, gene flow, NAOI, population structure, Salmo salar

Received 23 April 2010; revised version received 22 September 2010 and accepted 24 September 2010

\section{Introduction}

Biological invasions constitute one of the main risks for wild ecosystems. As aquatic environments generally exhibit less physical barriers to migration than terrestrial landscapes, which are typically patchy, they are particularly prone to invasions (e.g. Sala et al., 2000). Exotic fish species are large-scale invaders of freshwater systems in all continents, from Europe to America (e.g. Gido et al., 2004; Jeschke \& Strayer, 2005; Salmenkova, 2008), often following anthropogenic introductions. Salmonids are typical examples of deliberate humanmediated stock movements. For the purposes of fishing and aquaculture, they have been transferred to exotic regions such as South America and New Zealand, where they have adapted and in some cases become invaders (Pascual et al., 2002; Townsend, 2003; Valiente et al., 2007). Large-scale human-mediated stock move-

Correspondence: Eva Garcia-Vazquez, tel. + 34985 102726, fax

+34 985 103534, e-mail: egv@uniovi.es ments have also occurred between regions within the natural geographic range of a species; for example, in the second half of the XX century farmed salmon and trout from central and north European countries have been transplanted to south European rivers, where native populations already existed (e.g. Moran et al., 2005; Ayllon et al., 2006). Farmed salmonids have the potential for impacting on population productivity, disrupting local adaptations and reducing the genetic diversity of wild salmon populations (e.g. Fleming et al., 2000; McGinnity et al., 2009). It seems prudent to treat farmed fish as exotic species and to recognize the potentially negative consequences for wild populations, particularly when the latter are of conservation concern (Weir \& Grant, 2005). This is particularly the case for peripheral populations located at the edge of a species' range, for example, southern European Atlantic salmon populations $\left(42-43^{\circ} \mathrm{N}\right)$, which are declining (Parrish et al., 1998) and are recognized as being severely endangered (Prouzet, 1990). Projections for the future suggest that further reductions in their population sizes (Boylan \& Adams, 2006) are also likely. 
Climate change, however, has varied consequences for animal species: higher mortality in sheep (Hallett et al., 2004), variation in reproductive performance in marine birds (Croxall et al., 2002; Gjerdrum et al., 2003), changes in abundance, mortality and distribution of fishes (i.e. Finney et al., 2000; McFarlane et al., 2000, MacKenzie \& Koster 2004). Among the species potentially sensitive to global warming (De Young et al., 2004), the migratory Atlantic salmon (Salmo salar, Salmonidae) provides an opportunity for a case study because of its broad distribution on both sides of the Atlantic Ocean and its sensitivity to environmental effects, particularly temperature (Mills, 1991). Recent stock declines have been attributed in part to global climate change, which affects both juveniles and adults in diverse ways, from growth to migratory behaviour (e.g. Friedland et al., 2003, 2009; Jonsson \& Jonsson, 2004; Condron et al., 2005; Valiente et al., 2010). Another effect of climate change is the increase of sensitivity to invasions in aquatic ecosystems (e.g. Stachowicz et al., 2002; Rahel \& Olden, 2008), yet the influence of climate change on introgression of genomes from farmed lineages into wild Atlantic salmon populations has scarcely been explored.

In Atlantic salmon, it is commonly assumed that a strong homing instinct (returning to the natal river for reproduction; Lohmann et al., 2008) produces genetic isolation between populations inhabiting neighbouring rivers. Thus, the appropriate scale for biological conservation and management units tends to be at the level of an individual river, and large-scale genetic analysis across the species' distribution has demonstrated that this is generally true (King et al., 2001). Gene flow does occur between salmon populations, but is constrained by local adaptation at the regional scale and is influenced by both coastal distance and temperature regime (Dionne et al., 2008). Valiente et al. (2010) have recently demonstrated that warm climate conditions tend to increase straying and, consequently, gene flow among salmon in southern French rivers. It is also known that, as a consequence of the abundant deliberate stock transfers of the XX century, foreign genomes native to northern European countries have introgressed into southern European populations, contributing to the erosion of population structuring (Moran et al., 2005; Ayllon et al., 2006). Therefore, between-river genetic differences appear to have been diminished by the concomitant effects of two factors, human-mediated introgression of alien genomes and a climate-mediated increase in gene flow. Such a reduction of the spatial component of genetic diversity could destroy local adaptations, reducing population fitness (Utter, 2004). In the present circumstances of global climate warming, it is crucial to follow the evolution of those introgressed populations for preventing, if possible, future risks to vulnerable populations.
The case study presented here focuses on the largest Atlantic salmon populations in northern Spain, the natural southern edge of the species' distribution in Europe. Until 1992, local populations were supplemented with fish from a range of foreign stocks (originally from northern regions such as Ireland, Norway, Iceland and principally Scotland), which produced small but significant (up to 9\%) introgression of foreign genomes (Ayllon et al., 2006). Populations are currently managed by limiting catches per angler and conducting supportive breeding (Machado-Schiaffino et al., 2007; Horreo et al., 2008) and we expect that foreign genomes introduced in the past are being diluted in those populations because farmed and nonnative individuals released in the wild generally exhibit less fitness than native ones, e.g. Garcia-Vazquez et al., 1991; McGinnity et al., 1997, 2009; Martinez et al., 2001; Finnegan \& Stevens, 2008.

The question addressed in the current study is, is it possible to disentangle the relative weights of climate and fisheries management in shaping contemporary regional population genetic patterns? Using microsatellite loci as genetic markers we determined gene flow and the level of population structuring in the region of Asturias in northern Spain, and estimated the relative effects of human-mediated introgression and climatedriven migration on the population pattern encountered in 4 different years over the last three decades.

\section{Materials and methods}

\section{Sample collection}

In total, 924 tissue samples (adipose fin biopsy or scales) taken from returning adult Atlantic salmon captured by anglers were analyzed from five rivers in the region of Asturias in northern Spain (Eo, Esva, Narcea, Sella and Cares rivers; Fig. 1). The samples were collected during the angling and reproductive seasons (March-July and November-December, respectively) in the years 1988, 1996, 2002 and 2007, and were preserved in ethanol (fin) or dried (scales) until analysis. Approximately, 50 individuals were analyzed for each river per year, except for the river Narcea in 1988 (26 samples) and the river Eo in 1996 (21 samples). Samples from the river Sella were not available in 1988. The samples obtained each year covered all cohorts returning to the river that year (in these rivers lifespan is 4 years, adults being generally aged 1.1, 2.1, 1.2 , or 2.2, where the first number represents the number of years in the river and the second the number of years at sea).

\section{Climate index}

The North Atlantic Oscillation Index (NAOI) measures fluctuations in sea-level air pressure between the Atlantic subpolar low-pressure zone around Iceland and the subtropic 


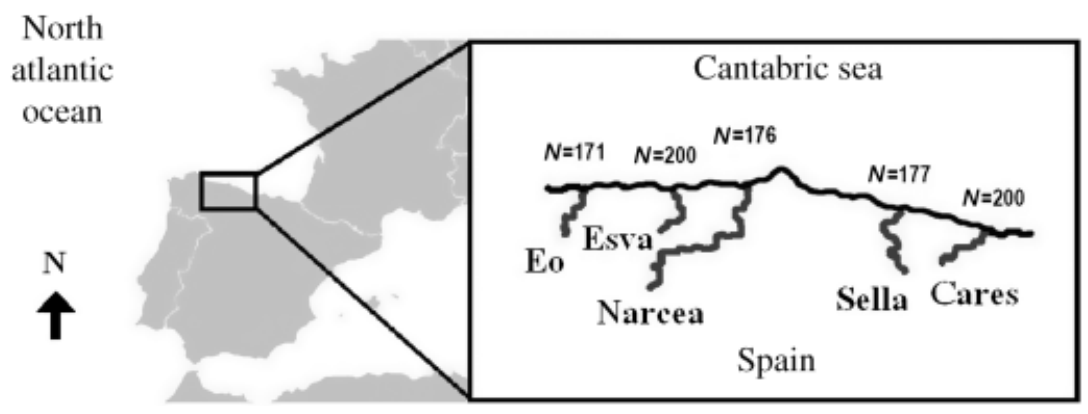

Fig. 1 Geographic location of the five rivers studied (Eo, Esva, Narcea, Sella and Cares) in northern Spain. N, total sample size for each river.

high-pressure zone around the Azores (Hurrell, 1995). We have chosen the normalized index Lisbon minus Stykkisholmur for the winter (December-March), obtained from http:// www.cgd.ucar.edu/ jhurrell. The use of the winter index is due to the fact that during this season the NAOI has the greatest effect on sea temperatures and hydrographic variability (Marshall et al., 2001; Ottersen \& Stenseth, 2001; MacKenzie \& Koster, 2004). Since the model species considered in this study is sensitive to climate oscillations in different life stages, and there are generation overlaps with breeders of different ages each year (e.g. Juanes et al., 2007), we have used the average NAOI of the 4 years of the species lifespan in this region as a proxy for the climatic conditions of each sampling period.

\section{Stocking data}

The juveniles released in the region for supplementing natural populations were obtained from two different sources: imported from commercial hatcheries in other countries (foreign transfer, FT), or from supportive breeding (the F1 generation produced from the artificial spawning of adults returning to the five rivers which are caught annually in the spawning season). In the second case, ova of one female are fertilized with sperm of one or two males. Embryos are reared in a hatchery and fed until the parr (juvenile) stage. Parr are released into the rivers of the region, most often in the river of origin of the breeders (autochthonous, A) or, less commonly, into another river within the region (regional transfer, RT).

Data concerning the release of parr were obtained from the Consejería de Medio Ambiente del Principado de Asturias, the administration in charge of managing the species in the region (jeronihr@princast.es). Reliable stocking reports with number of individuals released in each river were only available since 1981. Before that date, activity of FT had been reported only sporadically and therefore cannot be quantified.

\section{DNA extraction and polymerase chain reaction methodology}

Genomic DNA was extracted from tissue samples using Chelex resin (Estoup et al., 1996). Nine microsatellite loci were analyzed: SSsp2210, SSspG7 and SSsp1605 (Paterson et al., 2004), Ssa197 and Ssa202 (O'Reilly et al., 1996), SSOSL417, SSOSL85 and SSOSL311 (Slettan et al., 1995), and SS4 (Martinez et al., 1999).

PCR amplifications were performed on reaction mixtures containing about $50 \mathrm{ng}$ of salmon DNA, $10 \mathrm{nM}$ Tris. $\mathrm{HCl} \mathrm{pH}$ 8.8, $2.5 \mathrm{mM} \mathrm{MgCl}_{2}, 50 \mathrm{mM} \mathrm{KCl}, 0.1 \%$ Triton X-100, $0.35 \mathrm{~mm}$ of fluorescently labelled primers, $0.5 \mathrm{U}$ of DNA Taq Polymerase (Promega, Fitchburg, WI, USA) and $250 \mu \mathrm{M}$ of each dNTP in a final volume of $20 \mu \mathrm{L}$. Annealing temperatures were: $52^{\circ}$ (SSOSL417), $55^{\circ} \mathrm{C}$ (SSspG7, SSOSL85 and SSOSL311), $56^{\circ} \mathrm{C}$ (Ssa202), $60^{\circ} \mathrm{C}$ (SS4 and SSsp2210) and $61^{\circ} \mathrm{C}$ (SSsp1605 and Ssa197). Possible contamination was checked by negative extraction and PCR controls. Size determination of the labelled PCR products was performed using an ABI 3100 automatic DNA Sequencer and the GENEMAPPER V.3.5 (Applied Biosystems, Foster City, CA, USA) software at the DNA Sequencing Unit of the University of Oviedo.

\section{Estimates of genetic variability}

Genotyping errors (null alleles and large allele dropout) were checked with the MICROCHECKER software (Van Oosterhout et al., 2004). The computer program GENETIX (Belkhir et al., 2004) was used for calculating sample variability and genotype frequencies. Conformity with Hardy-Weinberg equilibrium and linkage disequilibrium were calculated with GENEPOP (Raymond \& Rousset, 1995). Microsatellite polymorphism in the region was quantified by allelic richness, gene diversity between samples $\left(F_{\mathrm{ST}}\right)$, observed $\left(H_{\mathrm{O}}\right)$ and expected $\left(H_{\mathrm{S}}\right)$ heterozygosity, relatedness (Rel) and corrected relatedness (Relc), and compared between sampling years using the program FSTAT version 2.9.3.2 (Goudet, 1995).

\section{Population structure}

Population structure across the region in each year of sampling was assessed using the program STRUCTURE 2.3.1 (Pritchard et al., 2000). This software estimates using a Bayesian method the minimum number of population units with a partial genetic identity in a dataset. The output from STRUCTURE provides $\operatorname{Ln} P(D)$ values for a given number of genetic units 
in a dataset for each run. These values increase along $K$ (the number of genetic units considered) until becoming stable. The number of genetic units is estimated in a conservative way, choosing the minimum number when $\operatorname{Ln} P(D)$ becomes stable. The program organizes the dataset in groups of samples being a part of the same genetic unit. Parameter set: Length of Burn-in Period: 50000, Number of MCMC Reps after Burn-in: 500 000, five runs for each $K$.

\section{Estimates of migration rates}

The estimates of the number of migrants between rivers $(\mathrm{Nm})$ in each year were based on the private allele methodology of Barton \& Slatkin (1986), using the program GENEPOP (Raymond \& Rousset, 1995) with the following settings: 1000 dememorization steps, 100 batches, 1000 interactions per batch. Gene flow between populations was also estimated by Rho-values (Slatkin, 1995), which are based on differences in allele frequencies between populations, with the RSTCALC software (Goodman, 1997) using 1000 permutations and 1000 bootstraps.

\section{Estimates of introgression of foreign genomes}

Introgression of foreign genomes (mostly Scottish) had been estimated already for 1988 (Moran et al., 2005) and 1997 (Ayllon et al., 2006) samples. For reasons of internal consistency of the study we have applied the same methodology as used by Ayllon et al. (2006), based on the Monte-Carlo simulation implemented within the IMMANC program (Rannala \& Mountain, 1997). Individuals of foreign origin (immigrants of first, second and consecutive generations) were identified based on their microsatellite genotypes (with 10000 replications).

\section{Principal component analysis (PCA)}

A PCA was carried out using the PAST version 1.90 software (Hammer et al., 2001) to find hypothetical variables (components) which account for variance in multidimensional datasets of genetic characteristics (parameters of genetic variability, number of genetic units, estimated introgression) and environmental factors (NAOI) of the studied populations. Significant components of the PCA were identified, based on the Jolliffe cut-off value (Jolliffe, 1986), as those providing Eigenvalues $>0.7$. The program estimates the proportion of variance contributed by each component, and the sign (positive or negative) and relative contribution of each factor (in this case each population characteristics) within each component. The data were analyzed with default settings and the 'correlation matrix' option. A correlation matrix (linear $r$-values) was obtained with the same software before the PCA, to identify those factors or parameters which were significantly correlated $(P<0.05)$. To avoid internal bias, one factor of each pair of significant correlates was eliminated from the PCA.

\section{Results}

\section{Stocking history and foreign introgression}

Two periods with markedly different stocking strategies can be identified (Table 1). The first period, from 1981 to 1992, was characterized by intense FT activity with some minor stocking of types A and RT. In the second period (1992-2007), both RT (at low level) and A stocking were carried out. FT represented between $13.1 \%$ and $59.7 \%$ (Sella and Eo rivers, respectively), RT between 0\% (Narcea and Cares rivers) and 9.1\% (Eo river) and $\mathrm{A}$ was $31.2-86.7 \%$ (Eo and Sella rivers, respectively) of the total number of individuals released in a river during the last three decades (1981-2008). In summary, three populations were stocked mainly with native salmon (Narcea, Sella, Cares, 76-87\% of historical releases) and two populations were stocked with both foreign and native salmon (Eo, Esva), with regional transfers being scarce.

\section{Variation at microsatellite loci}

Variability was generally high in all samples (Table 2), with mean number of alleles per locus ranging from 9.5 to 12.1 in the Eo and Sella rivers, respectively. No evidence of scoring errors, allelic dropout or stuttering was detected with the MICROCHECKER software, except at

Table 1 Documented releases (in thousands of juveniles) of hatchery-reared Atlantic salmon into the main Asturian rivers from 1981 to 2008

\begin{tabular}{|c|c|c|c|c|c|}
\hline \multirow[b]{2}{*}{ Origin } & \multicolumn{5}{|c|}{ Enhanced river } \\
\hline & Eo & Esva & Narcea & Sella & Cares \\
\hline Eo & 188.8 & - & - & - & - \\
\hline Esva & - & 466.6 & - & - & - \\
\hline Narcea & 60 & 1.2 & 2975.2 & 7 & - \\
\hline Sella & - & - & - & 4551.5 & - \\
\hline Cares & - & - & - & 2.5 & 1731.4 \\
\hline Scotland & 356 & 383 & 328.5 & 368.5 & 390.3 \\
\hline Iceland & - & 25 & 73.1 & 63.5 & 110.7 \\
\hline Ireland & 50 & 127.5 & 239 & 212.6 & 25 \\
\hline Norway & 10 & 33 & 40 & 42.5 & 8.5 \\
\hline Total FT & $\begin{array}{l}416 \\
(59.7 \%)\end{array}$ & $\begin{array}{l}568.5 \\
(54.8 \%)\end{array}$ & $\begin{array}{l}640.6 \\
(17.7 \%)\end{array}$ & $\begin{array}{l}687.1 \\
(13.1 \%)\end{array}$ & $\begin{array}{l}534.5 \\
(23.6 \%)\end{array}$ \\
\hline Total RT & $\begin{array}{l}60.0 \\
(9.1 \%)\end{array}$ & $\begin{array}{l}1.2 \\
(0.1 \%)\end{array}$ & 0 & $\begin{array}{l}9.5 \\
(0.2 \%)\end{array}$ & 0 \\
\hline Total A & $\begin{array}{l}188.8 \\
(31.2 \%)\end{array}$ & $\begin{array}{l}466.6 \\
(45.1 \%)\end{array}$ & $\begin{array}{l}2975.2 \\
(82.3 \%)\end{array}$ & $\begin{array}{l}4551.5 \\
(86.7 \%)\end{array}$ & $\begin{array}{l}1731 \\
(76.4 \%)\end{array}$ \\
\hline
\end{tabular}

FT, foreign transfer (1981-1992); RT, regional transfer (19921996); A, autochthonous (1996-2008). 
Table 2 Genetic variability at the microsatellite loci considered in the five rivers studied across the four sampling years (allele range/number of alleles per locus, $\mathrm{Na}$ )

\begin{tabular}{llllll}
\hline Locus/sample & EO & ESVA & NARCEA & SELLA & CARES \\
\hline SSsp2210 & $124-164 / 8.0$ & $128-164 / 9.0$ & $112-164 / 9.0$ & $116-164 / 10.5$ & $124-164 / 9.5$ \\
SSsp1605 & $218-250 / 6.0$ & $218-246 / 6.0$ & $218-250 / 7.0$ & $214-250 / 7.5$ & $218-250 / 6.0$ \\
Ssa202 & $236-268 / 8.5$ & $236-272 / 9.5$ & $236-272 / 8.0$ & $236-268 / 8.0$ & $236-272 / 9.5$ \\
SSOSL417 & $155-209 / 12.7$ & $155-209 / 13.7$ & $157-207 / 12.0$ & $145-209 / 15.6$ & $157-207 / 13.5$ \\
Ssa197 & $171-259 / 9.2$ & $175-259 / 11.7$ & $175-259 / 12.7$ & $167-259 / 17.0$ & $171-263 / 16.0$ \\
SSspG7 & $116-212 / 12.0$ & $116-192 / 13.5$ & $108-208 / 11.0$ & $108-204 / 12.5$ & $116-188 / 12.5$ \\
SSOSL85 & $180-230 / 10.0$ & $180-228 / 13.2$ & $170-228 / 11.5$ & $124-228 / 12.3$ & $164-228 / 13.2$ \\
SS4 & $176-232 / 9.7$ & $176-238 / 11.2$ & $176-254 / 9.5$ & $176-254 / 10.3$ & $176-254 / 11.5$ \\
SSOSL311 & $122-164 / 9.2$ & $120-180 / 13.7$ & $124-168 / 11.7$ & $114-174 / 15.3$ & $120-180 / 15.5$ \\
Mean Na (SD) & $9.5(2.0)$ & $11.3(2.7)$ & $10.3(1.9)$ & $12.1(3.4)$ & $11.9(3.2)$ \\
\hline
\end{tabular}

Mean Na of the loci analyzed per population (SD in parentheses).

locus SS4 in years 2002 and 2007, which exhibited signs of null alleles and was eliminated from further analyses. Genotype frequencies at the remainder of microsatellite loci were mostly in Hardy-Weinberg equilibrium after sequential Bonferroni correction (about $80 \%$ of tests). When they were not in equilibrium, deviation was due to heterozygote deficit. No evidence of linkage disequilibrium (generated by physical linkage of pairs of loci) was observed within the dataset.

\section{Population structure and gene flow over time}

Population structure changed over the period considered, and was generally consistent with changes in stocking practices (Fig. 2). In the 1980s (FT-based management), the five rivers of the region exhibited population structure indicative of two genetic units. For $K=2$, maximum $\ln P(D)$ values [mean $\ln P(D)=-3493.92$, $\mathrm{SD}=3.13$ ] were obtained which were consistent across runs. The River Eo was alone in one cluster and the other three, Esva, Narcea and Cares rivers (there were no data for the River Sella), constituted another unit, with some mixture in the river Esva (Fig. 2). It should be noted that FT was more intense for the River Eo than for the rest (Table 1). In the 1990s (immediately post-FT), the five rivers may be considered to be one single genetic unit; the highest $\ln P(D)$ values, consistent across runs, were found for $K=1$ [mean $\ln P(D)=$ $-4803.76, \mathrm{SD}=0.28$; Fig. 2]. By 2002, about two generations later (generation length being 2.6 years in the region, Consuegra et al., 2005), the regional population structure suggested by the microsatellite loci was consistent with two genetic units [mean $\ln P(D)=-7950.72$ for $K=2, \mathrm{SD}=0.65$ ], which also corresponded well to geographic relationships between the clusters or rivers. One unit comprised the Eo and Esva rivers, located in the west of the region, with the other eastward unit comprising the Narcea, Sella and Cares rivers (Fig. 2). In 2007, after 5 additional years under only type-A stocking, at least three units were identified with the STRUCTURE software [mean $\ln P(D)=-7989.9$ for $K=3$, $\mathrm{SD}=1.51]$. One unit contained the westernmost river, the Eo, the second included the mixed rivers Esva, Narcea and Cares, and the third unit corresponded to the River Sella (Fig. 2).

The number of migrants per generation $(\mathrm{Nm})$ among the five rivers calculated using private alleles oscillated between 4.16 and 11.4 in 1988 and 2002, respectively (Table 3). When estimated using Rho-values, amongriver migration in the region followed similar oscillations. Overall, these results indicate that since the 1980s gene flow increased steeply until 2002 and decreased in 2007.

\section{Introgression of foreign genomes, climate indices and population genetic parameters}

Some individuals caught in the region were identified as immigrants (from the first to the fourth generation) in the four temporal periods analyzed: $2.16 \%, 6.81 \%$, $2.96 \%$ and $1.31 \%$ in the 1988, 1996, 2002 and 2007 samples, respectively (Table 3 ). The proportion of individuals with immigrant ancestors was at a maximum in 1996 and seemed to decrease later. The population genetic parameter $F_{\mathrm{ST}}$ and the number of genetic units $K$ (Table 3), also experienced fluctuations over time, following a similar pattern (increasing from 1988 to 1996, and then decreasing). A significant increase of mean allelic richness was found from 1988 to 1996 (7.264 and 9.132, respectively, $P$-value 0.026 ) and continued at a high level in the third and fourth sample years. The climatic index NAOI experienced high oscillations over the lifespan of the 1996 sample, ranging from -3.78 to 3.96, with somewhat less but still high variations in 

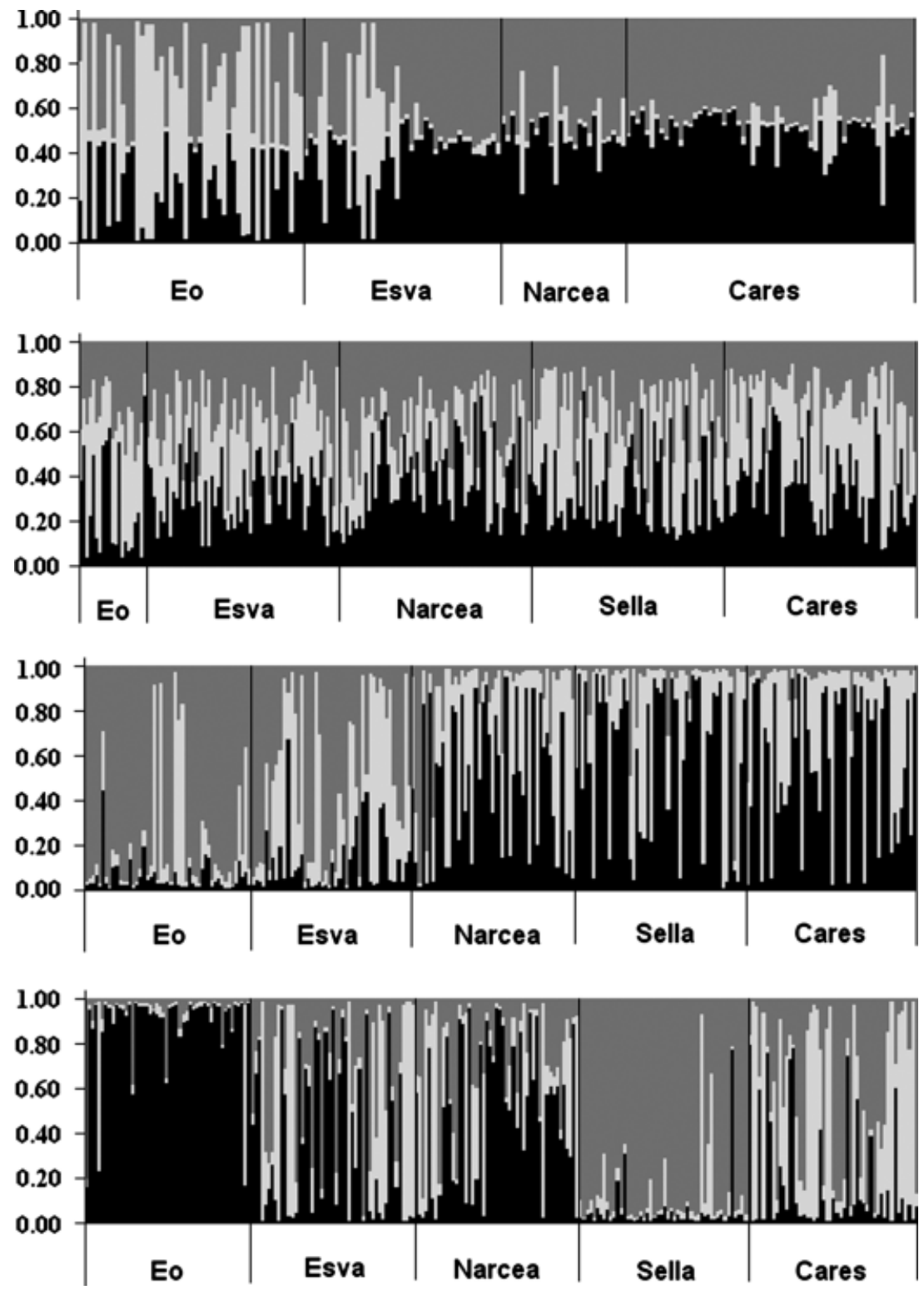

Fig. 2 Estimation of the membership fraction to each of three inferred clusters for North Spanish Atlantic salmon in (from top to bottom) 1988, 1996, 2002 and 2007, based on microsatellite loci. Each vertical bar represents one individual and vertical lines sticking out from the graph mark river limits. Each cluster is represented by one colour: dark grey, light grey, black. River Sella 1988 samples are missing.

those of the 2002 and 2007 samples. Maximum winter NAOI, however, was less pronounced and oscillations were lower for the lifespan of 1988 samples (Table 3). The 4-year average NAOI of 1996 was the highest and that of 1988 the lowest.

Although only four temporal points were studied, three significant correlations were found (Table 4). The two estimates of gene flow were also correlated to each other $(r=0.983, P=0.017)$. The level of introgression was positively associated with the expected heterozygosity $(r=0.982, P=0.018)$, as expected from introduc- tion of new alleles in a region. The global climate index NAOI was negatively associated with $F_{\mathrm{ST}}(r=-0,962$, $P=0.037$ ), indicating that warm conditions decrease between-population diversity. $\mathrm{F}_{\mathrm{ST}}$, expected heterozygosity and Rho estimates were eliminated from the PCA in order to reduce biases due to internal correlations between population traits.

The PCA identified two significant components (Table 5), accounting together for more than $95 \%$ of the variance. The main contributor for explaining the dataset variance within Component 1 (59\% variance) 
Table 3 Population structuring, climate indices and estimates of foreign introgression in Asturian Atlantic salmon

\begin{tabular}{lccccccccc}
\hline Year & NAOI & Migration (Rho) & Migration (Private) & $F_{\mathrm{ST}}$ & \multicolumn{1}{c}{ AR } & $H_{\mathrm{s}}$ & $H_{\mathrm{o}}$ & $K$ & Introgression \\
\hline 1988 & $-0.04[-0.75 / 0.72]$ & 2.12 & 4.16 & 0.053 & 7.264 & 0.782 & 0.669 & 2 & 2.16 \\
1996 & $1.47[-3.78 / 3.96]$ & 10.9 & 8.87 & 0.017 & 9.132 & 0.834 & 0.742 & 1 & 6.81 \\
2002 & $0.84[-1.89 / 2.8]$ & 12.7 & 11.34 & 0.027 & 10.346 & 0.784 & 0.731 & 2 & 2.96 \\
2007 & $0.44[-1.09 / 2.8]$ & 9.02 & 8.41 & 0.033 & 10.073 & 0.778 & 0.746 & 3 & 1.31 \\
\hline
\end{tabular}

NAOI, North Atlantic Oscillation Index (average value for the 4-year lifespan of the samples, range in brackets); Migration, gene flow estimated by Rho-values (Rho) and Private Allele methodology (Private); $F_{\mathrm{ST}}$ value, mean pairwise $F_{\mathrm{ST}}$ values between populations; AR, allelic richness; mean heterozygosity expected $\left(H_{\mathrm{s}}\right)$ and observed $\left(H_{\mathrm{o}}\right)$; $K$, number of genetic units estimated using the program STRUCTURE; Introgression, regional introgression of non-native individuals as mean introgression of the rivers analysed.

Table 4 Correlation between genetic and climate parameters ( $r$-values for linear correlations and $P$-values, below and above the diagonal, respectively)

\begin{tabular}{lccccccccc}
\hline & NAOI & Migration (Rho) & Migration (Private) & $F_{\mathrm{ST}}$ & $\mathrm{AR}$ & $H_{\mathrm{s}}$ & $H_{\mathrm{o}}$ & $K$ & Introgression \\
\hline NAOI & 0 & 0.206 & 0.319 & $\mathbf{0 . 0 3 7}$ & 0.508 & 0.162 & 0.279 & 0.342 & 0.137 \\
Migration (Rho) & 0.793 & 0 & $\mathbf{0 . 0 1 7}$ & 0.094 & 0.098 & 0.668 & 0.124 & 0.834 & 0.607 \\
Migration (Private) & 0.680 & $\mathbf{0 . 9 8 2}$ & 0 & 0.187 & 0.073 & 0.828 & 0.188 & 0.937 & 0.748 \\
FST & $-\mathbf{0 . 9 6 2}$ & -0.905 & -0.812 & 0 & 0.298 & 0.319 & 0.122 & 0.569 & 0.304 \\
$\mathrm{AR}$ & 0.491 & 0.902 & 0.926 & -0.701 & 0 & 0.955 & 0.117 & 0.724 & 0.984 \\
$H_{\mathrm{s}}$ & 0.837 & 0.332 & 0.171 & -0.680 & -0.044 & 0 & 0.662 & 0.135 & $\mathbf{0 . 0 1 7}$ \\
$H_{\mathrm{o}}$ & 0.721 & 0.875 & 0.81 & -0.877 & 0.882 & 0.337 & 0 & 0.954 & 0.695 \\
$K$ & -0.657 & -0.165 & -0.063 & 0.430 & 0.275 & -0.864 & 0.045 & 0 & 0.075 \\
Introgression & 0.862 & 0.392 & 0.252 & -0.695 & -0.015 & $\mathbf{0 . 9 8 2}$ & 0.305 & -0.924 & 0 \\
\hline
\end{tabular}

Significant values $(>0.05)$ in bold.

Table 5 Principal component analysis of the dataset

\begin{tabular}{lccc}
\hline & Component 1 & Component 2 & Component 3 \\
\hline \% variance & $59.336(3.559)$ & $36.737(2.204)$ & $3.933(0.236)$ \\
NAOI & $\mathbf{0 . 5 0 0 2}$ & -0.2172 & 0.1488 \\
Gene flow & $\mathbf{0 . 4 6 2 8}$ & 0.2535 & -0.6373 \\
Allele richness & 0.398 & 0.4416 & -0.1624 \\
Heterozygosity & 0.4622 & 0.2587 & 0.6242 \\
Structure & -0.213 & $\mathbf{0 . 6 0 6 7}$ & 0.3398 \\
Introgression & 0.3437 & $-\mathbf{0 . 5 0 8 5}$ & 0.2006 \\
\hline
\end{tabular}

Percent of variance contributed by each component (Eigenvalue in parentheses) and by each factor within each component. Jolliffe's cut-off Eigenvalue: 0.7.

was NAOI, followed by migration (Table 5). Within Component 2, which accounted for almost $37 \%$ of the variance, the parameter measuring the level of population structuring ( $K$, the number of genetic units) and the level of introgression (in this case negative) were the most important quantitatively. Migration and heterozygosity $\left(H_{\mathrm{o}}\right)$ were almost coincident and indistinguishable in the scatter diagram (Fig. 3). Introgression and NAOI were both in the same direction and in the opposite direction of population structuring in the region (Fig. 3, negative $r$-values in Table 4); the NAOI projection was longer, indicating greater contribution to the dataset variance. Except for the number of genetic units (regional population structuring), the parameters: migration estimate, allelic richness and heterozygosity were projected as positive on the $X$-axis, as were introgression and NAOI, suggesting concomitant effects of the two latter factors with increased gene flow and within-population genetic diversity in the region.

\section{Discussion}

The results obtained in this study are consistent with high levels of migration among rivers in Spanish salmon. The rule of One Migrant Per Generation (OMPG, which is the maximum interchange allowed for considering two populations as independent; Mills \& Allendorf 1996) was easily surpassed during the period 1996-2007 (Table 3). Despite a marked homing instinct (Stabell, 1984), and significant population structuring in the region (Fig. 2), it seems clear that there is a significant level of interchange of breeders between rivers. This is reflected in lower $F_{\mathrm{ST}}$ values (Table 3) than those 


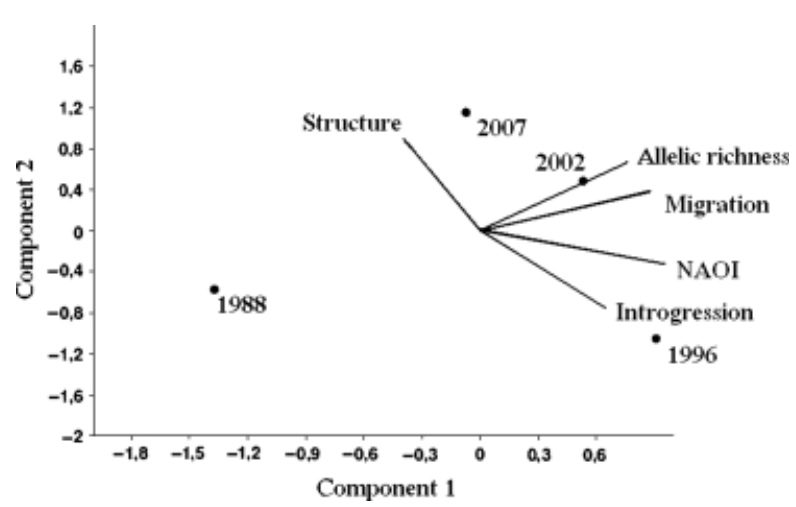

Fig. 3 Scatter diagram showing the principal components of the dataset. The length of the segments representing each factor is proportional to its relative weight in the principal component analysis (PCA).

reported by other authors at regional level for other latitudes (e.g. King et al., 2001). Genetic units comprised generally more than one river (Fig. 2), and mixture of different genetic units in the same river (migration) and mixed membership of some individuals was also observed.

At least part of the high levels of gene flow observed in salmon populations in northern Spain may be attributed to anthropogenic causes. Stocking with the same foreign stock released in all the rivers at the scale described in Table 1 appears to be the likely origin of at least some of the high levels of migration detected in our data, and this represents human-mediated migration. At the beginning of the studied period (1988) gene flow was higher than OMPG, and increased noticeably during the FT years, accompanied by a significant increase of allelic richness in 1996, which could be attributed to introgression of some foreign genomes into local populations (Ayllon et al., 2006). In the next period, the consequences of previous foreign stocking and stock transfers were observed, with parr transferred between rivers returning as adults 2 or 3 years later. In addition, the levels of straying, i.e. the return of adults back to nonnatal rivers, usually neighbouring rivers, to breed (Jonsson et al., 2003), are generally higher with hatchery-reared fish (Jonsson et al., 2003; Jonsson \& Jonsson, 2006), which may also have contributed to the high levels of migration observed in our data. The level of introgression decreased dramatically after 1996 (Table 3), which may indicate dilution of foreign genes in the wild gene pool consistent with decreased fitness of alleles originating from farmed individuals (e.g. McGinnity et al., 1997, 2009; Martinez et al., 2001).

However, introgression of foreign genomes was not the sole or even the main reason for oscillations in gene flow and, consequently, population structuring. Climate seems to be quantitatively more important, at least from the results observed in the PCA (Table 5) and the significant negative correlation between NAOI and $F_{\mathrm{ST}}$ (Table 4). Other climate indices such as the Atlantic Multidecadal Oscillation have also been found to be closely related with other Atlantic salmon population characteristics, such as recruitment (Friedland et al., 2009). In the present case, we have considered average NAOI for the entire lifespan of the adults sampled in the region, as, without many additional studies, it is not possible to determine the exact moment or life stage when the population structuring was eroded. Long datasets of well-monitored populations (survival at hatching, juvenile growth, smolt age, age at maturity, fertility and many other traits) could serve for this purpose, and would facilitate investigation of the association of population data with various climate indices (NAOI, Atlantic Multidecadal Oscillation, others). Between-river migration of adults, or straying and entering a nonnatal river when returning from the sea, are possibilities; research by Valiente et al. (2010) for another region at the same latitude demonstrated that warm conditions enhanced straying, contributing to increased gene flow. Valiente et al. (2010) also reported indirect signals of increased contribution of freshwatermaturing males (juvenile-like or precocious parr) under warmer climate conditions; such a finding suggests that an increased contribution to spawning by mature male parr of foreign origin, which are known to be responsible for at least some genome introgression at this latitude (Moran et al., 1994), may also play a role in eroding population structuring. Thus, synergistic effects related to a warmer climate may act to accelerate the homogenizing effect of human-mediated introgression, even after the cessation of introductions of foreign stocks.

Critically, this study changes our perception of the current status of Atlantic salmon populations at the southern-most limit of their natural distribution, emphasizing the importance of considering anthropogenic management as an artificial source of gene flow and population homogenization added to (and likely enhanced by) climate effects. Human intervention (stocking) is known to have reduced population structuring in other species, for example, partridge (Chen et al., 2006), chukar (Barbanera et al., 2007) and many others (Laikre et al., 2006). In Atlantic salmon, hatchery releases may threaten genetic integrity of even geographically distant wild salmon populations (Vasemägi et al., 2005). The escape or deliberate introduction of captive bred animals into the wild can substantially depress natural recruitment and more specifically can disrupt the capacity of natural populations to adapt to 
higher winter water temperatures associated with climate variability (McGinnity et al., 2009). In addition, our results suggest that in the present conditions of accelerated climate warming the risk is even higher, because warm conditions will likely enhance mobility of hatchery individuals among rivers in a region. When a species is sensitive to climate, as are Atlantic salmon (Friedland et al., 2003; Jonsson \& Jonsson, 2004; Condron et al., 2005), conservation programmes should be analyzed on a case-by-case basis and the population model assessed for each.

\section{Acknowledgements}

We thank Ivan G. Pola for his laboratory work. We are grateful to Jerónimo de la Hoz for helping with sampling. This study has been financially supported by European Union INTERREG projects 040 (ASAP), 203 (ASAP-2) and AARC. J. L. Hórreo holds a Research Contract funded by the FICYT within the Project IB09-0023. G. Machado-Schiaffino was supported by the EU Framework 7 project SALSEA-Merge. We are grateful to two anonymous GCB reviewers for very helpful comments on this manuscript.

\section{References}

Ayllon F, Martinez JL, Garcia-Vazquez E (2006) Loss of regional population structure in Atlantic salmon, Salmo salar L., following stocking. ICES Journal of Marine Science, 63, 1269-1273.

Barbanera F, Guerrini M, Hadjigerou P et al. (2007) Genetic insight into Mediterranean chukar (Alectoris chukar, Galliformes) populations inferred from mitochondria DNA and RAPD markers. Genetica, 131, 287-298.

Barton NH, Slatkin M (1986) A quasi-equilibrium theory of the distribution of rare alleles in a subdivided population. Heredity, 56, 409-415.

Belkhir K, Borsa P, Chikhi L, Raufaste N, Bonhomme F (2004) GENETIX 4.05, logiciel sous WindowsTM pour la génétique des populations. Laboratoire Génome et Populations, CNRS UPR 9060. Université de Montpellier II, Montpellier.

Boylan P, Adams CE (2006) The influence of broad scale climatic phenomena on long term trends in Atlantic salmon population size: an example from the River Foyle, Ireland. Journal of Fish Biology, 68, 276-283.

Chen Y, Zhao Z, Liu N (2006) Genetic structure of Przewalski's rock partridge (Alectoris magna) populations in the Longzhong Loess Plateau, China. Biochemical Genetics, 44, 209-221.

Condron A, DeConto R, Bradley RS, Juanes F (2005) Multidecadal North Atlantic climate variability and its effect on North American salmon abundance. Geophysical Research Letters, 32, L23703.

Consuegra S, Verspoor E, Knox D, de Leaniz CG (2005) Asymmetric gene flow and the evolutionary maintenance of genetic diversity in small, peripheral Atlantic salmon populations. Conservation Genetics, 6, 823-842.

Croxall JP, Trathan PN, Murphy EJ (2002) Environmental change and Antarctic seabird populations. Science, 297, 1510-1514.

De Young B, Heath M, Werner F, Chai F, Megrey B, Monfray P (2004) Challenges of modeling ocean basin ecosystems. Science, 304, 1463-1466.

Dionne M, Caron F, Dodson JJ, Bernatchez L (2008) Landscape genetics and hierarchical genetic structure in Atlantic salmon: the interaction of gene flow and local adaptation. Molecular Ecology, 17, 2382-2396.

Estoup A, Largiader CR, Perrot E, Chourrout D (1996) Rapid one-tube DNA extraction for reliable PCR detection of fish polymorphic markers and transgenes. Molecular Marine Biology and Biotechnology, 5, 295-298.

Finnegan AK, Stevens JR (2008) Assessing the long-term genetic impact of historical stocking events on contemporary populations of Atlantic salmon (Salmo salar L.) Fisheries Management and Ecology, 15, 315-326.

Finney BP, Gregory-Eaves I, Sweetman J, Douglas MSV, Smol JP (2000) Impacts of climatic change and fishing on Pacific salmon abundance over the past 300 years. Science, 290, 795-799.
Fleming IA, Hindar K, Mjølnerød IB, Jonsson B, Balstad T, Lamberg A (2000) Lifetime success and interactions of farm salmon invading a native population. Proceedings Biological Sciences/Royal Society, 267, 1517-1523.

Friedland KD, MacLean JC, Hansen LP et al. (2009) The recruitment of Atlantic salmon in Europe. ICES Journal of Marine Science, 66, 289-304.

Friedland KD, Reddin DC, McMenemy JR, Drinkwater KF (2003) Multidecadal trends in North American Atlantic salmon (Salmo salar) stocks and climate trends relevant to juvenile survival. Canadian Journal of Fisheries and Aquatic Sciences, 60 563-583.

Garcia-Vazquez E, Morán P, Pendás AM (1991) Chromosome polymorphism patterns indicate failure of a Scottish stock of Salmo salar transplanted into a Spanish river Canadian Journal of Fisheries and Aquatic Sciences, 48, 170-172.

Gido KB, Schaefer JF, Pigg J (2004) Patterns of fish invasions in the Great Plains of North America. Biological Conservation, 118, 121-131.

Gjerdrum C, Vallée A, Cassady St Clair C, Bertram DF, Ryder JL, Blackburn GS (2003) Tufted puffin reproduction reveals ocean climate variability. Proceedings of the National Academy of Sciences USA, 100, 9377-9382.

Goodman SJ (1997) R-ST Calc: a collection of computer programs for calculating estimates of genetic differentiation from microsatellite data and determining their significance. Molecular Ecology, 6, 881-885.

Goudet J (1995) FSTAT (Version 1.2): a computer program to calculate F-statistics. Journal of Heredity, 86, 485-486.

Hallett TB, Coulson T, Pilkington JG, Clutton-Brock TH, Pemberton JM, Grenfell BT (2004) Why large-scale climate indices seem to predict ecological processes better than local weather. Nature, 430, 71-75.

Hammer $\varnothing$, Harper D, Ryan P (2001) Past: paleontological statistics software package for education and data analysis. Paleontologia Electronica, 4, 1-9.

Horreo JL, Machado-Schiaffino G, Griffiths A, Bright D, Stevens J, Garcia-Vazquez E (2008) Identification of differential broodstock contribution affecting genetic variability in hatchery stocks of Atlantic salmon (Salmo salar). Aquaculture, 280, 89-93.

Hurrell JW (1995) Decadal trends in the North Atlantic Oscillation: regional temperatures and precipitation. Science, 269, 676-679.

Jeschke JM, Strayer DL (2005) Invasion success of vertebrates in Europe and North America. Proceedings of the National Academy of Sciences USA, 102, 7198-7202.

Jolliffe I (1986) Principal Component Analysis. Springer-Verlag, Berlin.

Jonsson B, Jonsson N (2006) Cultured Atlantic salmon in nature: a review of their ecology and interaction with wild fish. ICES Journal of Marine Science, 63, $1162-1181$.

Jonsson N, Jonsson B (2004) Size and age of maturity of Atlantic salmon correlate with the North Atlantic Oscillation Index (NAOI). Journal of Fish Biology, 64, 241-247.

Jonsson B, Jonsson N, Hansen LP (2003) Atlantic salmon straying from the River Imsa Journal of Fish Biology, 62, 641-657.

Juanes F, Perez J, Garcia-Vazquez E (2007) Reproductive strategies in small populations: using Atlantic salmon as a case study. Ecology of Freshwater Fish, 16, 468-475.

King TL, Kalinowski ST, Schill WB, Spidle AP, Lubinski BA (2001) Population structure of Atlantic salmon (Salmo salar L.): a range-wide perspective from microsatellite DNA variation. Molecular Ecology, 10, 807-821.

Laikre L, Palme A, Josefsson M, Utter F, Ryman N (2006) Release of alien populations in Sweden. Ambio, 35, 255-261.

Lohmann KJ, Putman NF, Lohmann CMF (2008) Geomagnetic imprinting: a unifying hypothesis of long-distance natal homing in salmon and sea turtles. Proceedings of the National Academy of Sciences USA, 105, 19096-19101.

Machado-Schiaffino G, Dopico E, Garcia-Vazquez E (2007) Genetic variation losses in Atlantic salmon stocks created for supportive breeding. Aquaculture, 264, 59-65.

MacKenzie BR, Koster FW (2004) Fish production and climate: sprat in the Baltic Sea. Ecology, 85, 784-794

Marshall J, Kushnir Y, Battisti D et al. (2001) North Atlantic climate variability: phenomena, impacts and mechanisms. International Journal of Climatology, 21, 1863-1898.

Martinez JL, Dumas J, Beall E, Garcia-Vazquez E (2001) Assessing introgression of foreign strains in wild Atlantic salmon populations: variation in microsatellites assessed in historic scale collections. Freshwater Biology, 46, 835-844.

Martinez JL, Moran P, Garcia-Vazquez E (1999) Dinucleotide repeat polymorphism at the SS4, SS6 and SS11 loci in Atlantic salmon (Salmo salar). Animal Genetics, 30, 464465 .

McFarlane GA, King JR, Beamish RJ (2000) Have there been recent changes in climate? Ask the fish. Progress in Oceanography, 47, 147-169.

McGinnity P, Jennings E, de Eyto E et al. (2009) Impact of naturally spawning captivebred Atlantic salmon on wild populations: depressed recruitment and increased risk of climate-mediated extinction. Proceedings of the Royal Society B, 276, 36013610 . 
McGinnity P, Stone C, Taggart JB et al. (1997) Genetic impact of escaped farmed Atlantic salmon (Salmo salar L.) on native populations: use of DNA profiling to assess freshwater performance of wild, farmed, and hybrid progeny in a natural river environment. ICES Journal of Marine Science, 54, 998-1008.

Mills DH (1991) Ecology and Management of Atlantic salmon. Chapman \& Hall, London.

Mills LS, Allendorf FW (1996) The one-migrant-per-generation rule in conservation and management. Conservation Biology, 10, 1509-1518.

Moran P, Pendas AM, Garcia-Vazquez E, Izquierdo JI, Rutherford DK (1994) Electrophoretic assessment of the contribution of transplanted Scottish salmon Salmo sala to the Esva river (Northern Spain). Canadian Journal of Fisheries and Aquatic Sciences, 51, 248-252.

Moran P, Perez J, Dumas J, Beall E, Garcia-Vazquez E (2005) Stocking-related patterns of genetic variation at enzymatic loci in south European Atlantic salmon populations. Journal of Fish Biology, 67, 185-199.

O'Reilly PT, Hamilton LC, McConnell SK, Wright JM (1996) Rapid analysis of genetic variation in Atlantic salmon (Salmo salar) by PCR multiplexing of dinucleotide and tetranucleotide microsatellites. Canadian Journal of Fisheries and Aquatic Sciences, 53, 2292-2298.

Ottersen G, Stenseth NC (2001) Atlantic climate governs oceanographic and ecological variability in the Barents Sea. Limnology and Oceanography, 46, 1774-1780.

Parrish DL, Behnke RJ, Gephard SR, McCormick SD, Reeves GH (1998) Why aren't there more Atlantic salmon (Salmo salar)? Canadian Journal of Fisheries and Aquatic Sciences, 55, 281-287.

Pascual MA, Macchi P, Urbansky J, Marcos F, Riva Rossi C, Novara M, Dell'Arcipreste $P$ (2002) Evaluating potential effects of exotic freshwater fish from incomplete species presence-absence data. Biological Invasions, 4, 101-113.

Paterson S, Piertney SB, Knox D, Gilbey J, Verspoor E (2004) Characterization and PCR multiplexing of novel highly variable tetranucleotide Atlantic salmon (Salmo salar L.) microsatellites. Molecular Ecology Notes, 4, 160-162.

Pritchard JK, Stephens M, Donnelly PJ (2000) Inference of population structure using multilocus genotype data. Genetics, 155, 945-959.

Prouzet P (1990) Stock characteristics of Atlantic salmon Salmo salar in France: a review. Aquatic Living Resources, 3, 85-98.

Rahel FJ, Olden JD (2008) Assessing the effects of climate change on aquatic invasive species. Conservation Biology, 22, 521-533.
Rannala B, Mountain JL (1997) Detecting immigration by using multilocus genotypes. Proceedings of the National Academy of Sciences USA, 94, 9197-9201.

Raymond M, Rousset F (1995) GENEPOP (version 1.2): population genetics software for exact tests and ecumenicism. Journal of Heredity, 86, 248-249.

Sala OE, Chapin FS, Armesto JJ et al. (2000) Global biodiversity scenarios for the year 2100. Science, 287, 1770-1774.

Salmenkova EA (2008) Population genetic processes in introduction of fish. Russian Journal of Genetics, 44, 758-766.

Slatkin M (1995) A measure of population subdivision based on microsatellite allele frequencies. Genetics, 139, 457-462.

Slettan A, Olsaker I, Lie O (1995) Atlantic salmon, Salmo salar, microsatellites at the SSOSL25, SSOSL85, SSOSL311, SSOSL417 loci. Animal Genetics, 26, 281-282.

Stabell OB (1984) Homing and olfaction in salmonids - a critical review with special reference to the Atlantic salmon. Biological Reviews of the Cambridge Philosophical Society, 59, 333-388.

Stachowicz JJ, Terwin JR, Whitlatch RB, Osman RW (2002) Linking climate change and biological invasions: ocean warming facilitates nonindigenous species invasions. Proceedings of the National Academy of Sciences USA, 99, 15497-15500.

Townsend CR (2003) Individual, population, community and ecosystem consequences of a fish invader in New Zealand streams. Conservation Biology, 17, 38-47.

Utter FW (2004) Population genetics, conservation and evolution in salmonids and other widely cultured fishes: some perspectives over six decades. Reviews in Fish Biology and Fisheries, 14, 125-144.

Valiente AG, Beall E, Garcia-Vazquez E (2010) Population genetics of south European Atlantic salmon under global change. Global Change Biology, 16, 36-47.

Valiente AG, Juanes F, Nuñez P, Garcia-Vazquez E (2007) Is genetic variability so important? Non-native salmonids in South America. Journal of Fish Biology, 71, 136-147.

Van Oosterhout C, Hutchinson WF, Wills DPM, Shipley P (2004) MICRO-CHECKER: software for identifying and correcting genotyping errors in microsatellite data. Molecular Ecology Notes, 4, 535-538.

Vasemägi A, Gross R, Paaver T, Koljonen ML, Nilsson J (2005) Extensive immigration from compensatory hatchery releases into wild Atlantic salmon population in the Baltic Sea: spatio-temporal analysis over 18 years. Heredity, 95, 76-83.

Weir LK, Grant JWA (2005) Effects of aquaculture on wild fish populations: a synthesis of data. Environmental Reviews, 13, 145-168. 